\title{
Between Motherland and Fatherland: Rootlessness and the Indian Jewish Identity in a Post-Colonial Context
}

\author{
Smita Singh
}

\begin{abstract}
Minorities in any country face the threat of being marginalized and pushed to the periphery. Marginality for the members of minority groups remains an involuntary position ascribed to them. As seen in most minority discourses, the question of identity is central and is subject to several aspects related to the situation of the particular minority group in the context of its position of existence in the said country or culture. Minorities can be defined on the basis of culture, language, religion, ethnicity, colour, caste or any other virtue attributed to a particular group. This paper is an attempt to explore the Post-Colonial identity of members of a miniscule minority, the Bene Israel Jews, who have lived and survived and also managed to maintain their distinct identity in the multi-cultural canvass of India. It tries to explore the crisis faced by this community specially in the context of bridging a gap between their Motherland which is India and their Fatherland which is Israel. It looks into the divided identity of this Jewish community which is Indian by citizenship and Israelite by religion. The primary text in question and the major point of reference for this paper shall remain Meera Mahadevan's fictional work Shulamith. This paper shall additionally look into the fictional works of other Indian Jewish writers as well. As the titular character of the novel Shulamith searches for a homeland in India, this paper will evaluate her struggles as a voice from a religious minority in India. When the State of Israel came into being in 1948, Jews started returning to Israel in search of better opportunities. Mahadevan's character struggles in the midst of an alien culture to stick to her own identity as an Indian Jew. Though her roots remain in Israel she is completely committed to a homeland which she finds in India.
\end{abstract}

Keywords: Motherland, Fatherland, Rootlessness, Identity, Indian Jew, Post-Colonial.

Jews in India for ages have lived a peaceful life, even as they still continue to negotiate their status as a microscopic minority following a monotheist foreign religion in the context of India where the majority follows polytheism. There are at least three major Jewish communities living in India namely the Bene Israel Jews, the Baghdadi Jews and the Cochini Jews. Other than these three major communities there are a few more minor Jewish settlements but their Jewish ancestry has yet to be completely authenticated. The classification of the three Jewish communities has been made on the basis of the places of their origin, in other words, the places from where they came and settled in India. The time of arrival of each Jewish community is different and has always remained under discussion as there is no authentic written records which can support the various claims.

This paper seeks to study the post-colonial identity of Indian Jew specially in the 
context of the Bene Israel community which is said to have arrived in India in 175 B.C.E., according to records presented in Haeem Samuel Kehimkar's, 1937 book The History of the Bene Israel of India.

Kehimkar, who was born in the Konkan region of Maharashtra and is popularly known as the historian of the community, writes in his book that the ancestors of the Bene Israel were shipwrecked near the Konkan coast in the village of Navgaon (about twenty miles south of Mumbai) in Raigadh district in 175 B. C. E. after they fled Palestine due to the persecution of Greek ruler Antiochus Epiphanes when Israel was under the control of the Greeks. The Greeks started imposing their religious views on the Israelites. The Israelites though made every effort to oppose the Greeks, were overpowered and persecuted. This is the time when the ancestors of the Bene Israel left their home country to escape the persecution and landed on the Konkan coast of India.

The Post-Colonial discourses can be traced back post the publication of Edward Said's seminal work Orientalism (1978). Research to assess the impact of colonial patterns of domination on the Jewish diasporas spread across the world has seen a recent rise. The Jews have always experienced the 'Otherness' in the lands where they have resided whether or not they have faced anti-Semitic attitude varies from place to place. In the context of India, Jews have always experienced a safe atmosphere though they may not have been accepted by the majority communities 'as their own'. "But they were always seen as different and thus deprived of the joy of full integration in the Indian society.... They were always seen as fellow human being, but could never be included among "our own people." (Rohekar, 2013, as cited in Aafreedi, 2014, p.69)

When translated, the Bene Israel simply means children of Israel. When they came to India, they lost everything they had. Only one truth remained that they were Children of Israel, a name which they chose for themselves. "The millennia long stay of the Bene Israel Jews in countryside India in absolute isolation from the rest of the Jewish world resulted in their complete acculturation...." (Aafreedi,2014, p.72) For thousands of years they have tried to negotiate their status as Indian Jews both in India and Israel and as most of the Bene Israel lament that they are treated as Jews in India and Indians in Israel, constantly under the tag of an alien identity.

The Indian independence (1947) almost coincided with the formation of the State of Israel (1948) following which the Jewish diasporas living across the world were summoned to return or make 'Aliyah' or ascent to Israel. With the migration of the Bene Israel community it was feared that the community might soon diminish in India. However, around five thousand Bene Israel still remain in India out of which around 2500 live in Mumbai alone. This paper seeks to analyze the post-colonial identity of an Indian Jew from the Bene Israel community with the main point of reference being Meera Mahadevan's novel Shulamith: A Novel (1975). Shulamith is the name of the titular character that faces a dilemma to choose between her Jewish and Indian identity. She already faces the brunt of displacement and seeks to find a homeland in India at the same time reconciling with her fractured displaced identity.

Over the past century scholarly interest has been generated to evaluate the Indian Jewish Identity. In recent discourses the Jewish identity in diasporas across the world are being discussed in the context of ethnicity, religion and nation. Nathan Katz writes in his book, "...ethnicity, nationality, community or peoplehood are fluid, which is to say that they are products of culture, adapt to social, economic and political change, and embody 


\section{Between Motherland and Fatherland: Rootlessness and the Indian Jewish Identity in a Post- Colonial Context}

distinctions deemed significant by a culture.” (Katz, 1995, p.6)

In the Indian context since the country was under the rule of British colonizers, Indian Jewish identity also needs to be analyzed in the context of the colonizer and the colonized. Keeping in mind the complicated history of the Jews who were subjected to several foreign invasions and subsequent exile and subjugation in their native land, it is interesting to analyze how they reacted to the political and social changes which were a result of colonization.

...in speaking of Jewish ethnic identity in India, one inevitably deals with caste. But superimposed on this traditional Indian structure was the British colonial presence, especially after 1857, when direct political rule over India was transferred from the British East India Company to the British Crown. Jews in India now became British subjects. (Roland, 2017, p.240)

During the British colonial period, India went through a series of transformations and changes. The Bene Israel were a completely rural community living an insignificant life as oil pressers. Mostly the members of the community would either be involved in this traditional trade or in agriculture. After the British came to India, they started developing Bombay (now Mumbai) as a major centre of their activity. Meanwhile, the community had already started migration towards the bigger cities from the Konkan coast in the later part of the eighteenth century.

Jewish identities in India went through a complete makeover in the colonial period. During the time of British rule, new opportunities began the process of urbanization among the Bene Israel Jews. "The first major impact of the British rule in India on the Bene Israel was their transformation from a predominantly rural community to a predominantly urban one." (Aafreedi, 2014, p.73) From the traditional oil pressers who were part of the rural Konkan belt, they became urbanized English-speaking Jews. From being members of a micro-minority community, which was numerically almost insignificant in India, a new awareness was created among the Bene Israel Jews that they were part of a larger world Jewish community spread across diasporas through the world.

After most Bene Israel moved to Bombay, they found themselves in a new worldmodernized, westernized, and Hebrewized. This was the beginning of the end of their Indian identity. "...The first strand, and all India rather than a specifically Bene Israel phenomenon, was the modernizing, westernizing ethos introduced by the British. The process was more crucial to the Bene Israel than to most other Indians because it signified the end of them as an Indian 'sub-caste."' (Katz, 2000, p.101)

A major part of the Bene Israel community made Bombay their home where they established their first synagogue in 1796 which was called the Sha'ar ha-Rahamin synagogue which is also known as the Gate of Mercy. The place where most of the Bene Israel community settled near this synagogue is still known as Israel Mohalla. However, now most of the people have settled in different localities and no Jewish families reside here.

When the British shifted their major trading port to Bombay, the city became a centreof trade and activity under the British regime. "As the British East India Company sought to expand its regiments there, they [Bene Israel] got absorbed in those regiments in increasingly large numbers under the caste name of Israel to an extent that at one point of time about half of the Indian officer strength of the Bombay Army consisted of Bene Israel, 
as estimate." (Aafreedi, 2014, p.73-74) The minority community found favour with the British as it politically insignificant and posed no threat to the supremacy of the British. Coming in contact with the British, they also were educated in the missionary schools which helped them to acquire proper skills and ultimately helped them secure jobs in skilled trades as well as in government services. They also found clerical jobs with private companies hence improving their financial condition. As the community gradually flourished in Bombay, more synagogues and prayer halls were established in adjoining areas and also in different parts of the city.

With the rise of the British empire, the spread of religion and missionary activities was at peak. Christian missionaries during the colonial period were greatly responsible for reconciling the Bene Israel Jews to their ancestral religion. Firstly, by translating their Bible and other religious books to the local Marathi language and secondly by teaching them Hebrew and English. "...the most important role in this religious revival was played by Christian missionaries, who strongly influenced the Bene Israel through their educational endeavours after the ban on missionary activities in India was lifted in 1813," (Aafreedi 74). The missionaries translated the Old Testament into the local Marathi language. They also developed Hebrew grammar in Marathi which gave the Bene Israel an access to their original religious texts written in the Hebrew language. As they studied in English medium schools, the knowledge of English language gave them access to the Jewish literature published in other foreign countries.

But despite much effort by the missionaries, the Bene Israel remained rooted in the tenants of Judaism and in fact developed stronger connections with their co-religionists across the world as a result of this, further strengthening their Jewish identity. During the same time, the Cochini Jews also came in contact with the Bene Israel in the first half of the nineteenth century. The Cochin Jews reconciled the Bene Israel with their lost Jewish identity which had almost diluted into the dominant cultures. The Cochin Jews reintroduced them to Jewish customs and their lost ancestral heritage.

At a time when the British-Indian relationship was that of superior-inferior, the identification of the Baghdadi community with the Europeans resulted in a social rift between them and the Bene Israel. The doubts expressed by the Baghdadis about the purity of descent and religious observances of the Bene Israel also contributed to the weakening of the Jewish fraternal ties. Perhaps it was the increasing rejection by their coreligionists, the Baghdadis, which led the Bene Israel to strengthen ties with the Jews abroad and engage with the Zionist movement. (Aafreedi, 2014, p.80)

This new-found awareness that they were a part of a larger Jewish community, the feeling of isolation and alienation gradually started diminishing among the Bene Israel. Earlier, the missionaries and the Cochini Jews were their only bridge to Judaism. But this new found knowledge directly linked them with the Jews living in other diasporas. It only further strengthened their Jewish brotherhood and the feeling that they had a nation which belonged to them was a huge attraction. Other than this feeling of belongingness which was created under the colonial impact, every Jew wanted to return to the Promised land in keeping with promises of their Holy scriptures. They believe that the Messiah would return only after the remanent of Israel would return to the Holy land. The Bene Israel who had earlier completely acculturated into the dominant cultures in India, now gradually started accepting their own Jewish identity more strongly than before. Several Jewish festivals were reintroduced to them and several others were modified according to the general belief of the Jews world over. However, several cultural practices still remained indigenous to the Bene 


\section{Between Motherland and Fatherland: Rootlessness and the Indian Jewish Identity in a Post- Colonial Context}

Israel community.

Three characters from Meera Mahadevan's novel have been assessed to study the impact of colonial rule on their identities. First is the titular character Shulamith who accepts her identity which is in the middle space. Shulamith as an Indian Jew does not possess a pure identity which can be classified into any one category either Indian or Jew. Moreover, she already faces the brunt of displacement as in her young age, her family was displaced from Karachi after riots broke out in the aftermath of India-Pakistan partition.

She already faces rootlessness after unfavourable circumstances led to their displacement from the land of their birth. They had to settle in Maharashtra after the Jewish synagogues were targeted by angry mobs in the riots which hit both India and Pakistan after the partition. "But one day the Karachi synagogue was looted by Muslim refugees. Why did they do it? Were they urged to it by the Arab-Israeli conflict? But we are Indians. We have been here for so long, and we have never done anyone any hard." (Mahadevan, 1975, p.5657) The Jewish community living in Karachi decided to leave the newly formed Pakistan and settle down in India choosing Maharashtra as their home which was the place where their ancestors had settled when they first landed in India.

The only consolation we had was the fact that the local Muslims deeply regretted what had happened. They said, "This is done by hooligans. They are having a fieldday because of the partition. No that there are no Hindus to harass in Pakistan, they have spent their anger against the Jews."...It was then that the Bene-Israel community decided to leave Karachi for Bombay. (Mahadevan, 1975, p.58)

Soon after the British left, the Bene Israel suffered immensely. They did not understand how they should react to the Hindu Muslim violence. Mahadevan's character Shulamith describes her suffering as she remembers her home in Karachi. "It was then that the Bene-Israel community decided to leave Karachi for Bombay. Except a very few families they chose to re-settle in Bombay. It was a most important day when they left their own houses and started for this unknown city." (Mahadevan, 1975, p.58) She still cannot get over the feeling of displacement even after eight years of migrating from Karachi to Mumbai. In her heart she always belonged to Karachi, the place of her birth which was also part of India in pre-independence times. "Perhaps its is because we keep remembering Karachi. But they don't realize that it is impossible for us to forget the Karachi we knew. The older generation at least will never get used to Bombay." (Mahadevan, 1975, p.52)

It was little difficult for the Karachi Bene Israel people to identify with those living in Mumbai. Though they were bound by the same thread of Judaism, there weremarked cultural differences. The writer mentions at least twice in the novel how the Bene Israel of Karachi were different from those in Mumbai. The first difference that the writer points out is of food habits. "“We used to get excellent meat in Karachi. Perhaps that is why we prefer it to fish. But I find that in Bombay most people like fish more than meat."' (Mahadevan, 1975, p.52) The Mumbai Bene Israel community as they had always resided on the sea shore were particularly fond of sea fish whereas those from Karachi were more accustomed to mutton and other meat dishes. The other difference that she points out was in the way they celebrated their joyous occasions.

The only cheerful thing about her impending wedding seemed to be the presence of someone willing to sing the customary songs. Her neighbours in Panvel did not know how to sing and dance. But these Karachi people seemed ever ready to sing and 
dance. (Mahadevan, 1975, p.101)

Speaking to her husband Michael, Shulamith speaks of India as a land which had nourished them. "I told him that what India had done for her Bene-Israels, no nation could do for its Jewish population. India has nourished us. We continue to be so well looked after that we are now thoroughly Indianized." (Mahadevean, 1975, p.40)

The second character who is in question is Shulamith's husband Michael. When the State of Israel came into being, Jews from all over the world were called to resettle in their fatherland. People from Jewish diasporas began their assent or 'Aliyah' as they call it to Jerusalem in keeping with the scriptures which spoke of the Israelites to gather again in their own land. Michael who was not highly educated and ran his father's old shop had reconciled with the thought that returning to Israel and serving the Holy land was the duty of every Jew. After the British arrived in India, they established several schools with an intention to spread education as well as propagate their missionary activities and their religion. Most Bene Israel people registered in these British schools where along with English they were also taught their ancestral language Hebrew.

...access to the Bible confirmed the Bene Israel's identity as Jews. The missionaries also taught them Hebrew and English. As soon as the Bene Israel knew enough of the holy tongue, they translated Hebrew prayers into Marathi and composed Indian-style devotional songs known as kirtans. The Bene Israel studied English avidly, and it became their passport to Bombay, to the modern world, and to the Jews elsewhere. (Katz, 2000, p.95)

This new exposure to their ancestral language started a process of Hebrewization among the Bene Israel Jews. "As the Bene Israel became accultured to Jewish norms, they modified their self-understanding and their sense of place within India. Rather than emulate high -caste Hindu behaviours...they emulated more knowledgeable Jews, in a process of "Hebrewization." (Katz 2000, p.100). They became more aware of their identity as being part of the larger Jewish community which lived across diasporas in different nations and also in the native Israel. The awareness of first being a Jew rather than considering their nationality as the major part of their identity, Michael becomes determined that migration to Israel was the only solution to his personal crisis. It is only after he reaches Israel that he realizes how deeply rooted he was in the land of his birth.

The moment I left this country I realized how Indian I was. I may be Jewish but I cannot think or live like an American or Baghdadi Jew. I am an Indian, and my culture is an Indian culture. India is my country. I knew then that this was exactly what you were trying to tell me at a time when I paid no attention to you. One thing I have learnt is that one's country is as important as one's religion. (Mahadevan, 1975, p.203)

The Bene Israel Jews suffered double marginalization under the colonial impact. On the one hand, the Bene Israel Jews faced a lot of discrimination from their fellow Baghdadi Jews because of their skin colour. The Baghdadis, who tried to be closer to the British by imitating their culture and way of dressing, were somehow determined to raise questions about the purity of their race because of their darker skin colour. The Bene Israel were always seen being closer in looks to the native Indian races and hence fueling the suspicion that they were born as a result of mixed marriages between the Jews and the local communities. Since Jews gave a lot of importance to the purity of race, the ancestry of Bene Israel always 


\section{Between Motherland and Fatherland: Rootlessness and the Indian Jewish Identity in a Post- Colonial Context}

remained under question.

On the other hand, tough there was no anti-Semitism in India, the native Indian communities always saw the Bene Israel as outsiders. They were never accepted as completely Indian. This discrimination finally pushed the Jews towards the colonizer and they wanted to imitate the White Man's language and culture in order to gain acceptance. The problem remained that the inferiority complex instilled in the native person was too huge. He wanted an escape from being a non-white. Some found their escape in imitating the colonizer, others started searching for a home elsewhere.

...I start suffering from not being a white man insofar as the white man discriminates against me; turns me into a colonized subject; robs me of any value or originality; tells me I am a parasite in the world, that I should toe the line of the white world as quickly as possible, and "that we are brute beasts; that we are a walking manure, a hideous forerunner of tender cane and silky cotton, that I have no place in the world." So I will try and quite simply to make myself white; in other words I will force myself to acknowledge my humanity. (Fanon, 1967, p.78)

Most Bene Israel also found it as the best solution to migrate to Israel where they hoped that their existence would be easier with the co-religionist. They believed that shifting to Israel would make them part of the majority. Post-independence as they already bore the brunt of being the Other in India, they started the process of migration. However, the reality remained different. In India they were the Jews who followed and alien religion and in Israel they were branded as Indians who had doubtful ancestry. Once again acceptance in the majority community evaded them. For the rest of the Indian communities, when the British left India, they gradually started reconciling with their Indianness. Though many of them were anglicized to a certain level, there was peace with their native identities. But for the Jews, the alienation continued and more so because many Jews had gained favour with the British in terms of jobs and opportunities, they were treated with much contempt when the colonizers left. Perhaps migrating to a place where they could be the majority was the only rightful option for them.

....as they migrated and adapted to Israeli society, the Bene Israel's identity was again transformed. In modern India, they were seen as Jews and understood themselves as Jews. But in Israel, they were seen as Indians, just one more ethnic group (edah) among others. (Katz, 2000, p.95)

The third character under consideration is Michael and Shulamith's son Uriel. Uriel has completely reconciled with his new Jewish identity and given up his native identity as an Indian Jew. From the very beginning he hopes that his mother Shulamith would be convinced by his father's decision to migrate to Israel. Shulamith, however, sticks to her stand of being rooted in India. She could easily foresee what Michael could not see. She knew that though her identity as an Indian Jew existed somewhere in the in-between space, her whole existence was rooted in India. Besides she did not want to face the curse of displacement once again. She still felt the pain of being uprooted from Karachi and resettling on the Indian side in Maharashtra.

Michael tries to be the mimic and feels that he would be able to adjust to a completely new environment in Israel. Through the process of Hebrewiation he believed that he could mimic his Israeli co-religionists. But what he did not understand was that though they were 
all Jews, people living in Israel were Israelites and Michael was completely Indian in his habits and cultural practices. He faces defeat at both ends. When he returns to India after realizing that his true identity was of an Indian Jew, he loses the most valuable person in his life that is his wife Shulamith. Years of loneliness and mental strife had taken a toll on Shulamith. She passes away soon after Michael returns to India.

The Jews in India always suffer from a religion-nation dichotomy. They always face a dilemma whether to give preference to their Jewish identity or their existence as an Indian. The Bene Israel Jews continue to face ambivalence regarding their dual identity.

This ambivalence emanates out of their marginality in both Indian as well as Jewish society, given their peripheral positioning due to their function of possessing the elements and orientation of two cultures very different from each other, namely, Indian and Jewish, and at the same time being deprived of membership by both these cultures. (Aafreedi, 2014, p.71)

The problem is the dual identity which belongs to bother cultures which are completely distinct from each other. The sad part remains that they possess a marginalized position in both cultures. Shulamith is sure that she cannot adjust in a completely new country even though she revers the Holy land.

Daniel is another character in the novel who like Shulamith had accepted his existence in the in-between space. Daniel has elevated himself above the orthodoxy. Religion is not central to his life. Daniel always presents the rational point of view in the novel.

Both Fanon and Said believe that colonial impact has influenced identities of the colonized people but the crisis occurs due to the feeling of inferiority that is attached to everything which belongs to the colonized. This awareness of inferiority has been implanted by the Western systems. It affects the sense of true identity and sometimes the colonized person ends up giving up his native identity like in the case of Uriel. He disturbs his mother with the inevitable question, “"But Mama, don't you think we deserve a small of our own particularly after what happened to us during the World War II, and what we were mad eto suffer?"' (Mahadevan, 1975, p.92) Uriel is willing to give up his Indian identity in order to settle for a whole new Jewish world. Shulamith keeps herself grounded. She loves the Holy Land but knew that India was her home. "I am very proud of being Jewish; I love my religion and I have always tried to live according to its principles. The name of Jerusalem is as holy to me as my religion itself. Yet I do not want to go there," (Mahadevan, 1975, p.92). The dignity for Shulamith remains in accepting the in-between space that her hybrid identity provides her.

\section{References}

Aafreedi, N. J (2014). Between Indianness and Jewishness: The Ambivalence of Indian Jews As Reflected in Literature, Cinema And Art. In P. Singh et al. (Eds.), Beyond Strategies: Cultural Dynamics in Asian Connections. KW Publishers.

Fanon, Frantz (1967). Black Skin, White Masks, Grove Press.

Katz, Nathan (1995). Introduction, N. Katz (Ed.), Studies of Indian Jewish Identity(pp. 6). Manohar Publishers.

Katz, Nathan (2000). Who are the Jews of India?, Berkley, Los Angeles \& London: University of California Press.

Mahadevan, Meera (1975). Shulamith: A Novel. Arnold-Heinemann. 
Roland, J.G (2017). The Jewish Communities of India: Identity in a Colonial Era. London \& Routledge.

\section{$\underline{\text { Bio-note }}$}

Ms. Smita Singh is working as an Assistant Professor in the Department of English of the Lucknow Christian (Degree) College, a reputed institution in the City of Lucknow, Uttar Pradesh. She is currently also pursuing her PhD from the Department of English and Modern European Languages, University of Lucknow. Her research work explores the lives of the Bene Israel Jews, a miniscule religious minority concentrated in the State of Maharashtra and in the city of Ahmedabad in Gujarat. Being a student of literature, her research centres on fictional works of several writers coming from this minority community. 